\title{
The Detection of Fires in Micro-Gravity
}

\author{
MARTIN SHIPP and MICHAEL SPEARPOINT \\ Fire Research Station \\ Borehamwood, Herts, WD6 2BL, UK
}

\begin{abstract}
This paper describes a series of experiments carried out during parabolic flights to investigate the behaviour of fires in micro-gravity. Video recordings and the output from a range of instruments were recorded and analysed.

The study shows how different types of flame detector respond to the combustion of various fuel types. The results will be used to aid in the specification and design of the fire detection and suppression system for the European Space Agency space station Columbus.
\end{abstract}

KEYWORDS: Detection, Micro-gravity.

\section{INTRODUCTION}

Fire safety is a particular concern for the astronauts who will be living and working in the proposed International Space Station Freedom which is due to be launched towards the turn of the century. The Columbus Attached Pressurised Module (APM) will be the European contribution to Space Station Freedom.

On the earth's surface the movement of flames and smoke is strongly dependent on convection. In a space station with a "zero gravity" environment, natural convection is missing and therefore the combustion process may be expected to be very different.

The work described in this paper was carried out by the Fire Research Station (FRS) on behalf of the European Space Agency (ESA). Its purpose was to investigate the behaviour of fires in micro-gravity and to aid in the specification and design of the fire detection and suppression system for the Columbus module. Though the FRS study investigated a wide range of fire phenomena, this paper concentrates on those aspects of the research that were concerned with detection of fires in micro-gravity. The presentation of this paper includes video footage of the micro-gravity fire experiments.

\section{PREVIOUS STUDIES}

Fire experiments have been carried out in reduced gravity facilities since the space race of the 1960 's and there is a large body of published information available which it is not possible to reference in this paper. 
Previous published studies on fire behaviour in micro-gravity have investigated the change in the burning rates of different materials [1], [2], [3] in a range of atmospheres (chemical composition and pressure) and a number of studies [2], [4], [5] have reported the occurrence spherical-shaped blue flames. The flame produced by burning Pyrell foam observed by Bryant and Judd [2] was found to become almost invisible under true micro-gravity conditions and was very sensitive to accelerations. The micro-gravity fire experiments described by Kimzey [3], [6] showed that flames in micro-gravity conditions were difficult to record on film because of their near invisibility.

Very little published work is available on the response of various types of fire detection systems to micro-gravity flames. In 1965 Schreihens and Drysol [7] recommended that different types of flame sensing devices needed to be tested under micro-gravity conditions. Linford [8] describes the work carried out in the early 1970's for the UV flame detection system for Skylab using experiments conducted in a C-135 aircraft whilst executing Keplerian parabolas. Based on fire experiments conducted on Skylab in 1974, Kimzey [6] recommended that measurements of light emissions from the combustion of various materials needed to be made. Friedman and Urban [1] remark that no detailed measurements of electromagnetic radiation from micro-gravity fires have been published to date (1993).

Friedman and Olsen [9] discuss the current fire detection practice of using ionisation smoke detectors in space vehicles (such as those employed by the NASA Space Shuttle) and indicate the limitations of such systems. They suggest that flame detection may provide a better alternative.

\section{COLUMBUS MODULE DESIGN}

The current design of the APM Columbus is a cylinder $11.8 \mathrm{~m}$ long and $4.46 \mathrm{~m}$ in diameter. Life support equipment and services are provided in the 'sub-floor' and experiments will be located in separate packages along the 'walls' and 'ceiling'. Although a selection and control procedure for materials will be applied, it will not be possible to eliminate all combustible materials, particularly in the experimental packages and cabling. Materials will be assessed largely on the basis of terrestrial derived methods such as the Cone Calorimeter [10] and the Critical Oxygen Index Test [11].

The module will experience micro-gravity at all times except during manoeuvres. Currently air speeds within the module are expected to be between a minimum of $0.076 \mathrm{~m} / \mathrm{s}$ and a maximum of $0.203 \mathrm{~m} / \mathrm{s}$. The atmosphere may be 'ground normal' ie $21 \%$ oxygen at one atmosphere, though the design of the module may necessitate $34 \%$ oxygen at a reduced pressure equivalent to $7000 \mathrm{ft}$. Internal temperature will probably be between $18{ }^{\circ} \mathrm{C}$ and $27^{\circ} \mathrm{C}$ in habitable areas and a maximum of $37^{\circ} \mathrm{C}$ in non-habitable areas.

At the time of the FRS experiments, the proposed fire detection was designed around optical smoke detectors situated within the return air system of the ventilation (cooling) loops with dedicated temperature sensors located with high power consuming equipment. 


\section{THE FRS MICRO-GRAVITY FIRE EXPERIMENTS}

Two separate series of tests were carried out as part of this study. The first investigated the feasibility and practicalities of conducting micro-gravity fire experiments and provided some initial observations. The second series allowed measurements of various fire phenomena to be carried out using a modified version of the proven experimental rig.

The micro-gravity fire experiments were carried out as part of the two ESA Columbus campaigns of parabolic flights in March and October 1992. These campaigns were primarily intended to test the design of equipment being developed for Columbus. Each campaign consisted of three flights by a Novespace Caravelle aircraft which performed around 30 parabolas per flight. Each parabola lasted for a period of approximately 20 seconds.

\section{DESIGN OF FREE-FLOATING EXPERIMENTAL APPARATUS}

The experimental apparatus designed for the micro-gravity fire tests was intended to examine a number of fire processes which included the size, shape and colour of the flame; the effect of still or moving air; flame temperature; infra-red (IR) and ultra-violet (UV) radiation from the flame; combustion in an enhanced oxygen atmosphere and smoke and gas production.

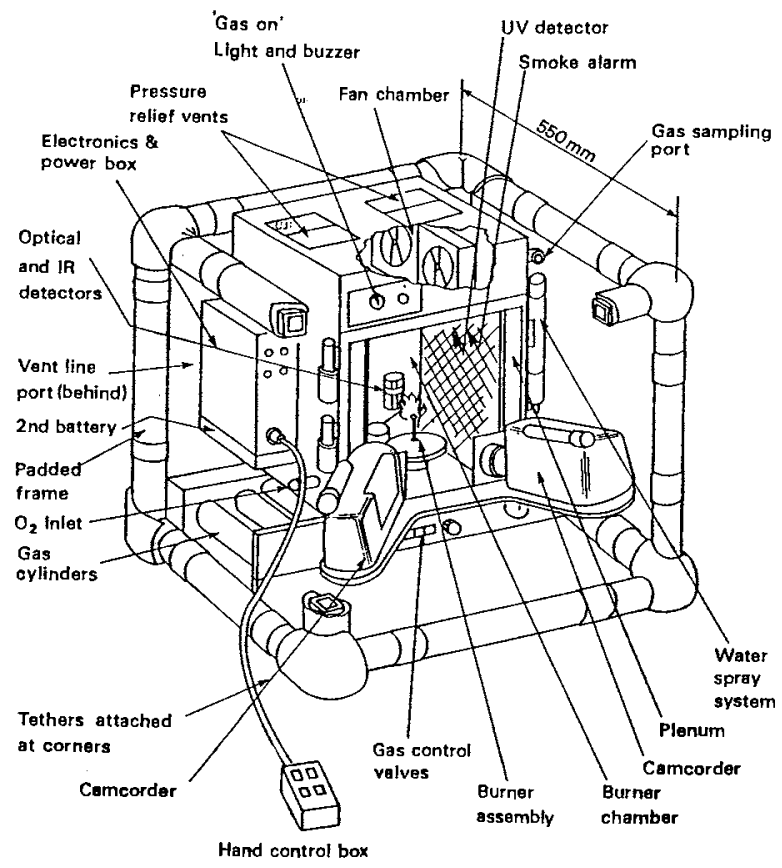

FIGURE 1. Free floating experimental rig, schematic
There were a number of design constraints imposed on the experimental apparatus due to the nature of the parabolic flights. Primarily the experiment had to be safe with appropriate measures taken where necessary and the experiment had to be compatible with other activities on the flights. The free-floating apparatus was to weigh no more than $25 \mathrm{~kg}$, it had to be able to withstand accelerations of up to 9-g and it had to fit through the aircraft door which limited its size to about $0.5 \mathrm{~m}$ by $0.5 \mathrm{~m}$ by $0.5 \mathrm{~m}$. The aircraft cabin pressure would be at the normal reduced pressure equivalent to $7000 \mathrm{ft}$. Each parabola was preceded by about 20 seconds of $1.8-\mathrm{g}$ (pull-up) and followed by 20 seconds of 1.8-g (recovery). Between recovery and pull-up for the next parabola was about 2 minutes of $1-\mathrm{g}$ during 
which time any preparatory activity for the next experiment would have to be conducted.

Figure 1 shows a schematic diagram of the experimental rig. The free-floating apparatus was loosely tethered to keep it within a defined working volume and to avoid impact with the cabin walls. The principal components and the apparatus were contained within a steel frame which was padded for protection. Mounted in the frame was an aluminium burner chamber $0.3 \mathrm{~m}$ by $0.3 \mathrm{~m}$ by $0.3 \mathrm{~m}$. The chamber was sealed by an aluminium door with a $13.3 \mathrm{~mm}$ thick polycarbonate window.

Above the burner chamber was the fan chamber which contained two adjustable speed fans. Air from the fans blew into a plenum on the left side of the burner chamber and re-circulated from the right side. Fine control of the airflow could be achieved by blocking off vent holes between the fan chamber and the plenum. An explosion relief vent was fitted in the lid. An electronics and power box was mounted on the chamber. $A$ hand held control box was connected to this unit by a flexible umbilical cable.

Propane was stored in ten small cylinders each with its own control valve. The amount of gas in one cylinder was such that if fully dispersed in the fire compartment the resultant mixture would be well below the lower explosive limit. Furthermore, the total amount of gas carried on the rig was such that if it all dispersed into the cabin the lower explosive limit would not be reached.

Different burner units were used; a small flat burner had thermocouples attached; the jet burner had mounting rails for solid targets. Each burner unit had keyhole slots to engage it to the base-plate allowing it to be easily removed from the rig and quickly replaced. The ignition system consisted of a high tension coil which discharged via a relay controlled by the hand box providing a spark to the bumer.

Two domestic 'Video- 8 ' video camcorders were mounted at about $55^{\circ}$ to each other on a support bracket attached to the burner chamber door. Each camera had an anti-reflection shield around its lens. An additional camera was mounted in the aircraft cabin to record activity around the experiment.

An analogue UV detector was mounted within the fire chamber. This was a commercial flame detector which was modified electronically to provide a continuous output. The detector was based on a gas discharge tube which operated on the Geiger-Müller Principle. The tube, material and electrodes were designed to be sensitive to UV wavelengths of between 185 and $245 \mathrm{~nm}$. A UV photon striking the cathode causes an electron to be emitted, this collides with a molecule of the ionisable gas with sufficient energy to emit an electron from the gas molecule. Thus a small chain reaction takes place, the electrons produced are attracted to the anode which is at a potential of approximately 300 volts and a small current pulse is produced.

A photo/IR diode was mounted in a container positioned within the chamber. This device, TFK type BPW41N, had a peak response at $940 \mathrm{~nm}$.

Four $0.1 \mathrm{~mm} \mathrm{~K}$ type thermocouples were positioned on a frame on the small flat burner unit. One thermocouple was located $5 \mathrm{~mm}$ directly above the burner, the other three thermocouples were horizontally spaced $25 \mathrm{~mm}, 45 \mathrm{~mm}$ and $75 \mathrm{~mm}$ respectively from the nearest thermocouple. 
A commercially-available domestic portable ionisation smoke detector was modified so that the indicator light was visible on the exterior of the apparatus and the sounder was removed. The detector was fitted to the roof of the fire chamber.

The signals from the detectors and the thermocouples were recorded on an Acorn Archimedes A410 personal computer through a series of electronic amplifiers and a fast analogue digital converter (input range \pm 5 volts). Custom written software recorded the data to the computer's hard disk drive and floppy disc drive. The real-time output from the computer was super-imposed on a view from one of the door mounted video cameras using a 'Genlock' interface allowing the experimenter to observe the progress of the tests during the flights.

The gas flow setting was calibrated on the ground to give the equivalent gas flow rate.

Thermocouples were calibrated by imposing an external voltage onto the instrument line, where the voltage applied was that equivalent to a specified temperature. For each thermocouple an individual calibration curve was generated and this was used to convert the raw thermocouple voltage data into a temperature. Due to design limitations, the thermocouples did not have a $0^{\circ} \mathrm{C}$ cold junction and therefore all temperature measurements were recorded as a difference from ambient.

The optical detector had a wide spectral response which included infra-red. It was not possible to calibrate the instrument in terms of its energy input. However, for the purposes of this study it was more important to investigate whether a micro-gravity flame gave any detectable infra-red or optical emission. Thus the optical detector was calibrated in a dark room to give a comparative reading using different gas burner settings ie different gas flow rates in 1-g. Raw data from the micro-gravity experiments could be converted to an equivalent $1-\mathrm{g}$ gas burner flame.

The output from the modified UV detector was not smooth since each photon impingement on the sensor gave a measurable discharge. Various calibrations of the UV detector were feasible, for example, it would be possible to determine the frequency of discharge with a particular gas setting. However, with only a maximum of 20 seconds of micro-gravity available during any single parabola and the frequency of discharges comparable low it was not possible to perform such a correlation. An increasing discharge frequency also gave an increasing "average reading". Unfortunately, close examination of the UV records from the micro-gravity experiments showed that the discharge amplitude, which was reasonably consistent during calibration, was significantly different on some flights. This was possibly due to low voltage on the battery which powered the UV detector. Thus, no actual calibrations were used in the analysis but the results from the UV detector was used as a method of investigating whether a micro-gravity flame gave any detectable UV emission. It was not practicable to calibrate either of the flame detectors for the solid materials.

The air speed within the fire chamber were measured on the ground with the fans at various settings using a thermistor anemometer inserted into the fire chamber. Very low velocities were recorded, at the limits of the sensitivity of the instrument and consequently the measurements can only be used as a guide to velocities achieved. At maximum fan speed settings, an air speed of around $0.130 \mathrm{~m} / \mathrm{s}$ was measured at the burner. The minimum measured air speed was $0.01 \mathrm{~m} / \mathrm{s}$. 


\section{EXPERIMENTAL PROGRAMME}

The gas burner tests examined the following parameters; different burner types; various gas flow settings (setting $10,25 \mathrm{cc} / \mathrm{min}$ to setting $90,200 \mathrm{cc} / \mathrm{min}$ ) and the effect of various air flow speeds.

For solid materials the parameters examined were; material type; normal or enhanced (27-29\%) oxygen atmospheres and the effect of air flow. The jet burner was used as an ignition source.

The materials used were filter paper ( $0.2 \mathrm{~mm}$ Whatman No. 2$)$, unbleached cloth $(0.23 \mathrm{~mm}$ thick), balsa wood $\left(0.8 \mathrm{~mm}\right.$ or $3 \mathrm{~mm}$ thick) and hexamethylene tetramine $\left(\mathrm{C}_{6} \mathrm{~N}_{4} \mathrm{H}_{12}\right)$. Each sample was mounted onto a $1.38 \mathrm{~mm}$ thick aluminium frame, $90 \mathrm{~mm}$ by $90 \mathrm{~mm}$ with a $70 \mathrm{~mm}$ diameter central hole. Samples were glued onto the frames using sodium silicate glue.

For all of the combinations of parameters tested video records were made and, as far as possible, measurements of temperature and detector response were recorded. In a number of tests additional measurements were taken but these are not detailed in this paper.

\section{RESULTS}

On the initial campaign 101 parabolas were experienced and 46 fires were video recorded. The second campaign consisted of 90 parabolas with over 60 fires video recorded. Due to various instrument failures and interruptions, data were not logged for all parabolas. Much of the interpretation of the results has been made from the video records of the fires and the activity in the aircraft.

A great volume of data was recorded and it is not possible to present the results of all of the tests in this paper. Instead a detailed analysis of three selected tests is made here. The traces on the raw data plots are off set vertically so that they can be easily distinguished from each other.

Figure 2 shows an annotated plot of the raw data from the data logging system for the gas burner at setting 30 . The optical detector shows a response that matches the visible appearance of the flame. During periods in which the rig was floating freely, the flame became blue or invisible and no output was recorded by the detector. The spikes on the optical record are correlated with accelerations of the rig such as when the rig was man-handled by a crew member. At ignition, the optical detector gave an output equivalent to its 1-g gas setting. As the flame became invisible, as indicated by the video record, the output dropped to a value determined by the ambient light level within the aircraft cabin. During periods of acceleration, the optical detector again responded with a maximum equivalent $1-\mathrm{g}$ gas setting of $50(133 \mathrm{cc} / \mathrm{min})$.

However, in contrast to the optical detector, the UV detector record shows a steady stream of discharges both whilst the rig was floating freely and under acceleration. The discharge frequency for this test was approximately 48 counts per minute and the output was visually equivalent to a $1-\mathrm{g}$ gas flow of setting $10(25 \mathrm{cc} / \mathrm{min})$. 


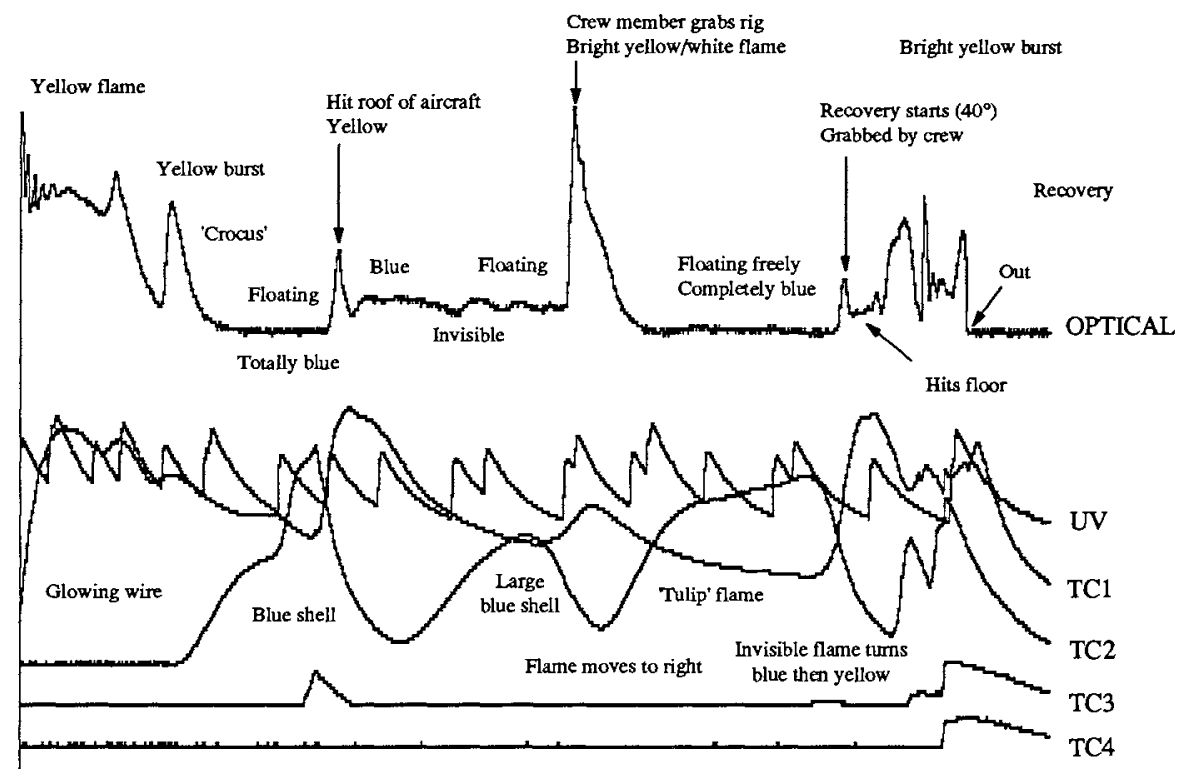

FIGURE 2. Raw data plot of gas burner fire (annotated from video records)
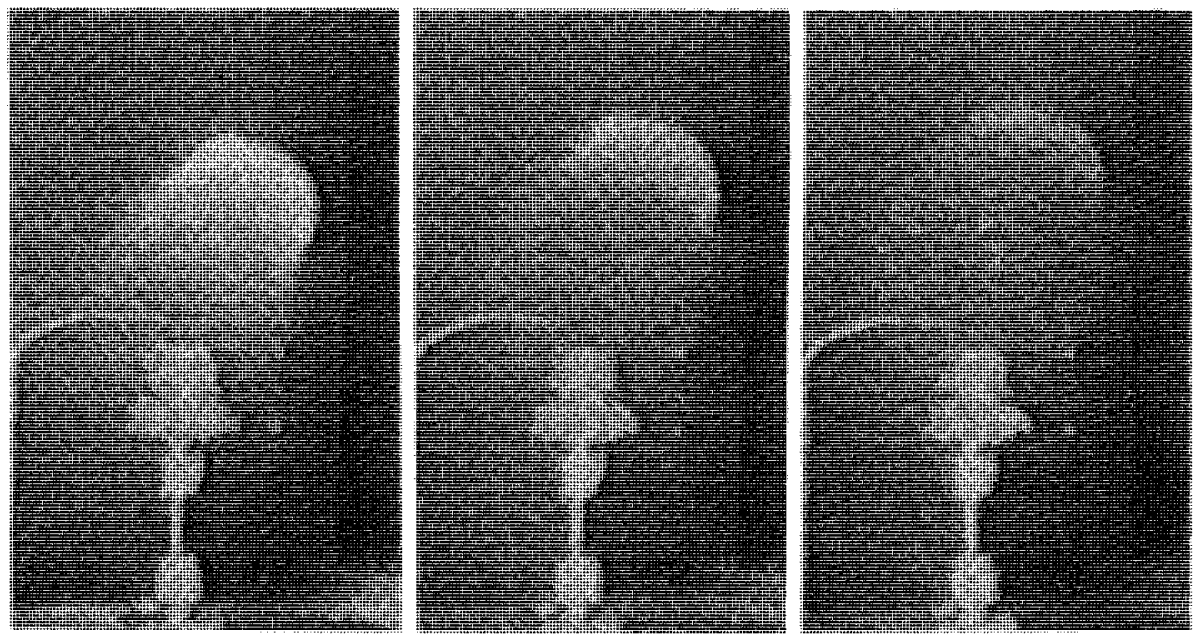

FIGURE 3. Sequence of photographs showing gas burner flame

As the flame became invisible the temperatures recorded by the thermocouples indicated that combustion was still taking place. Elevated temperatures in the region of $600^{\circ} \mathrm{C}$ indicated 
that combustion was taking place in the form of a spherical shell around the burner. At the same time, temperatures recorded by the burner thermocouple dropped. This phenomenon is also visible on the video recordings where the thermocouple wires are seen to glow sometimes in two separated locations. Calibrations at $1-\mathrm{g}$ gave temperatures around $1000^{\circ} \mathrm{C}$ in the flame, as would be expected.

The diameter of the spherical gas flame has been found to have a correlation with the logarithm of the gas flow rate. Figure 3 shows a typical micro-gravity gas bumer flame just before it becomes invisible.

An annotated raw data record for the combustion of a paper sample is shown in Figure 4. The fans were off for this test. The UV detector only responded whilst the jet burner flame was being used. Once the paper had ignited and the jet burner flame was extinguished the UV detector failed to respond to the fire.

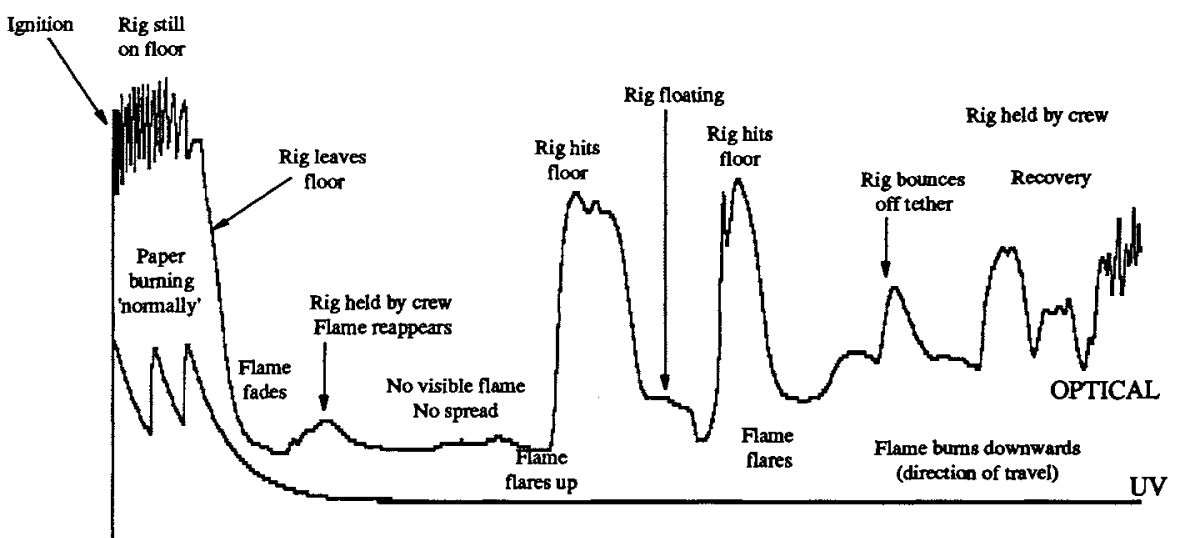

FIGURE 4. Raw data plot for paper fire (annotated from video records)

The optical detector continued to register an output during the test only while the flame was visible. When the flame was in true micro-gravity, the fire appeared to be extinguished and the optical detector only registered the ambient light level in the aircraft cabin. However, under acceleration, the flame reappeared and was again registered by the optical detector.

Figure 5 shows an annotated raw data record for a hexamethylene tetramine fire. The flame became spherical and continued to burn with a pale visible flame during the parabola. The UV detector responded to the fire throughout the test. The discharge frequency is less than for the gas burner test described above and was visually similar to the 1-g gas flow 5 setting (approximately $10 \mathrm{cc} / \mathrm{min}$ ).

However, apart from the period in which the jet burner flame was used to ignite the sample, the optical detector failed to give any significant output above the ambient level.

The gas burner flames turned into a pale blue sphere which, under normal lighting conditions, became invisible to both the naked eye and the video camera. 


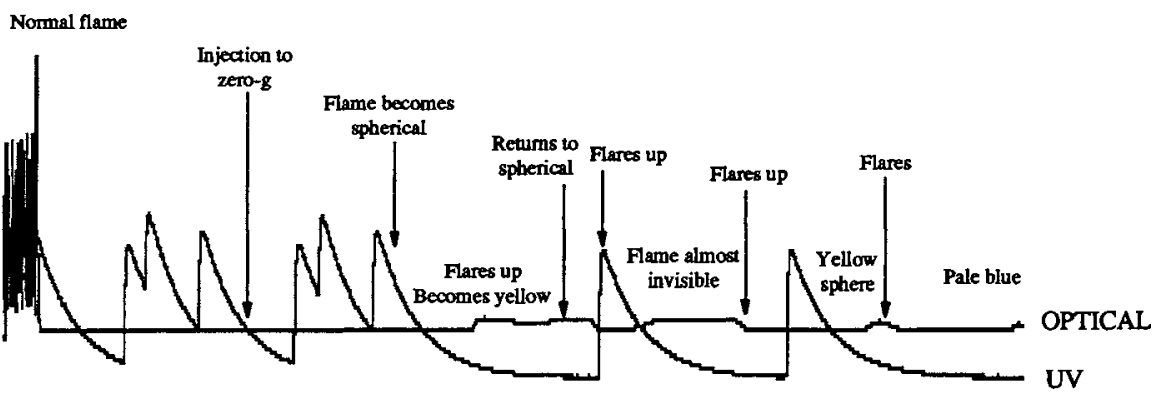

FIGURE 5. Raw data plot for hexamethylene tetramine fire (annotated from video records)

The flame had no preferred direction but moved around the burner as the experimental rig experienced small accelerations. Under larger accelerations the flame reverted to a normal yellow flame, pointing in the direction of movement.

Interesting 'tulip-shaped' cusps appeared during transition from low gravity to micro-gravity.

Where micro-gravity flames were subject to forced ventilation, it was found that blue or invisible flame would tum yellow even at air velocities as low as $0.01 \mathrm{~m} / \mathrm{s}$.

The paper, cloth and wood fires all died back in micro-gravity with still air and in some cases self-extinguished. Under acceleration, the flames became visible and they all continued to burn in moving air. The hexamethylene tetramine continued to burn in microgravity and did not self-extinguish.

The presence of an enhanced oxygen atmosphere resulted in much more vigorous fires with no evidence of the fire self-extinguishing.

Very little visible smoke was seen during any of the tests, and where smoke was observed it appeared to be associated with flames under "low gravity" rather than micro-gravity.

The ionisation smoke detector operated on occasions during the solid material tests when the fans were operational. However, as all the fires were exposed to some periods of acceleration whilst they burned with a yellow flame, it has not possible to draw any useful conclusions.

The response of the flame detectors varied with the material being bumed. The blue/invisible gas flame did not register on the optical detector but continued to give a UV output. Paper, cloth and wood gave no UV output but registered on the optical detector. Hexamethylene tetramine did register on the UV detector, but gave no significant optical output.

\section{COMPARISONS WITH PREVIOUS STUDIES}

The flame characteristics observed in this study were similar to those described in other experimental work concemed with micro-gravity fires. In particular, the experiments 
described by Kimzey [6] observed that a flame from burning paraffin was not recorded on either colour film or IR sensitive film. In the FRS experiments, the absence of an optical signal was also observed with the gas burner flame.

The UV detectors used on Skylab and described by Linford [8] used a discharge counting technique to determine an alarm condition. The discharge rate was found to be approximately proportional to the intensity of the incident UV radiation and count rates of 35 per second would raise an alarm. The count rate from the FRS experiments were an order of magnitude less but this may have been due to differences in the circuitry.

\section{IMPLICATIONS}

The findings from the FRS micro-gravity fire experiments will aid in the specification and design of a fire detection and suppression system for the Colombus module. Many of the problems of detecting fires in the Colombus module using the proposed fire detection system have already been recognised by ESA.

The blue gas flame appeared to be a transition state leading to an invisible flame. The invisible flame may also form on burning solid materials. Such a flame would be very difficult to locate by eye. These micro-gravity flames are very sensitive to accelerations.

Despite the flame being invisible, the flame shell showed a maximum temperature of $880^{\circ} \mathrm{C}$ and the heat transfer processes are sufficient to cause wire to glow. Such a flame could probably cause combustible materials which came in contact to ignite or decompose.

The blue gas flame will turn yellow in low air speeds of around $0.01 \mathrm{~m} / \mathrm{s}$. This suggests that flames can be made visible with the use of the on-board ventilation system. However, solid materials, which self-extinguish in zero airflow, continue to burn in an airflow.

As already noted, the combustion of various materials in micro-gravity affect optical and UV sensors in different ways. Clearly the types of detector that can be used effectively for the Columbus module depends on the materials within the vehicle. It may be necessary to use a combination of sensor types to increase the detection capabilities of a system. Where such a combination is used, careful consideration of the detection algorithm is required [12].

The type of detector used by a detection system will dictate the siting of the sensors. Fires occurring in the sub-floor of the Columbus module may be difficult to locate. Flame sensors (such as IR and UV types) require that the flame be directly within their field of view.

Smoke sensors (such as ionisation and optical sensors) require sufficient smoke to enter their sensing chambers to be able to detect a fire. Therefore, for a smoke sensor to be effective, a fire must produce smoke and this smoke must be able to travel to the sensing head. In terrestrial conditions, smoke detectors are normally located on the ceilings of rooms etc where the buoyant thermal smoke layer forms. However, in micro-gravity, there is no thermal buoyancy and thus the direction of travel of any combustion products cannot be as easily predicted and thus the most suitable location for a detector is not apparent. Ventilation flow within a space vehicle will cause any combustion products to move in particular directions and these can be modelled using mathematically [13]. However, very little smoke was observed from any of the micro-gravity fires studied in the FRS tests. 
In addition, different types of smoke sensors are more sensitive to different types of smoke. An ionisation sensor is better at detecting small smoke particles from a fast burning fire whilst an optical sensor is more suited to larger smoke particles from smouldering fires. Thus the performance and sensitivity of a smoke sensor for the detection of fires in spacecraft needs to be assessed with regard to the particle size range representative of combustion in micro-gravity.

Similar problems as those found with smoke sensors would be encountered with heat sensors. This study has shown that micro-gravity fires generate sufficient heat which could be detected with a heat sensor. However, the absence of thermal buoyancy in micro-gravity reduces the effectiveness of heat sensors unless they can be located close to a fire.

Because of the specific problems of getting smoke from a fire in micro-gravity into the sensing head of a smoke detector some space vehicle detection systems require that the ventilation system be operational at all times. However, this and other studies [7] have shown that a fire may self-extinguish if it is not subject to external air velocities. Thus a system that requires air movement may sustain a micro-gravity fire.

As with any fire detection system, the frequency of false alarms needs to be minimised without reducing the responsiveness of the system to an extent where it becomes ineffective. False alarm reduction in a space vehicle fire detection system has its own particular problems. For example, there may be sources of UV radiation which are not normally present on earth such as the proton flux present in near-earth orbit due to the trapped radiation belts or from scientific experiments in the vehicle. Such sources of false alarms were carefully considered with the Skylab fire detection system [14].

\section{CONCLUSION}

This study has been an aid to the specification and design of the Columbus fire detection system. Clearly, further study of the response of different types of flame sensor would be beneficial in the design of detection systems for the Columbus module and other space vehicles.

\section{ACKNOWLEDGEMENTS}

This work has been published with the permission of the European Space Agency. The authors would like to acknowledge the contribution of Knut Rygh and Jon Flidh of the Columbus Project Team and Peter Burry, Peter Fardell, Steve Andrews, Nigel Smithies, Bob Reboul, Dave Armitage, John Rowley, Simon Vollam, Bryan Bridgeman and other colleagues at the Fire Research Station.

\section{REFERENCES}

1. Friedman, R. and Urban D.L., Contributions of Microgravity Test Results to the Design of Spacecraft Fire-safety Systems. AIAA 93-1152. Aerospace Design Conference, Irvine, CA, 1993. 
2. Bryant, D. and Judd, M,. Polymer Group Microgravity Combustion Experiment in Combustion Experiments during KC-135 parabolic flights, SP-1113. ESA Publications Division, ESTEC, Noordwijk, The Netherlands, 1989.

3. Kimzey J.H., Zero Gravity Flammability. Space Processing and Manufacturing Symposium, ME-61-1, George C. Marshall Space Flight Center, Huntsville, Alabama, 1969.

4. Ross H.D., Sotos R.G. and Tien J.S., Observations of Candle Flames Under Various Atmospheres in Microgravity. Combustion Science and Technology, 75, 1-3, 155-160, 1991.

5. Durox D., Prud'homme R. and Scouflaire P., Premixed Flames in Microgravity in Combustion Experiments During KC-135 Parabolic Flights, SP-1113. ESA Publications Division, ESTEC, Noordwijk, The Netherlands, 1989.

6. Kimzey J.H., Skylab Experiment M749: Zero Gravity Flammability. Proceedings of the Third Space Processing Symposium, Vol.1, NASA MSFC M-74-5 (NASA TM X-70252), 1974, pp.115-130.

7. Schreihens F.A. and Drysol D.E., Flammability Characteristics of Some Organic Spacecraft Materials in Zero Gravity. North American Aviation Inc., SID 65-640, 1965.

8. Linford R.M.F., Experiments with the Skylab Fire Detectors in Zero Gravity. Paper No.8, NASA SP-298 pp.41-55, 1972.

9. Friedman R. and Olson S.L., Fire Safety Applications for Spacecraft. AGARD Conference proceedings No.467 Aircraft Fire Safety, AGARD-CP-467, 1989 pp.15-1 to $15-15$.

10. Fire Tests - Reaction-to-Fire - Rate of Heat Release from Building Products. ISO/DIS 5660 .

11. NASA Office of Safety and Mission Quality. Flammability, Odour and Offgassing Requirements and Test Procedures for Materials in Environments that Support Combustion. NASA specification NHB 8060.1C, 1991.

12. Friedman R. and Sacksteder K.R., Fire Behaviour and Risk Analysis in Spacecraft. NASA TM-100944, 1988.

13. Galea E.R. and Patel M.K., Columbus: Mathematical Modelling of Fire in Microgravity - Findings, Conclusions and Recommendations. ESA CR(P) 3296. Centre for Numerical Modelling and Process Analysis, Thames Polytechnic, London, UK, 1991.

14. Linford R.M.F., Integration of a Fire Detector into a Spacecraft. J.Spacecraft, 9, 9, pp.697-701, 1972. 